\title{
Establishment and Characterization of Feline Mammary Tumor Patient-Derived Xenograft Model
}

\author{
Hsiao-Li Chuang ${ }^{1,+} \oplus^{-}$, Yi-Chih Chang ${ }^{2,+}$, Yi-Ting Huang ${ }^{3}$, Jiunn-Wang Liao ${ }^{3}{ }^{\mathbb{C}}$, Pei-Ling Kao ${ }^{3}$, Yi-Fei Chen ${ }^{3}$, \\ Bin-Yin Lin ${ }^{3}$, Yi-Lo Lin ${ }^{3}$, Ter-Hsin Chen ${ }^{3}$ and Yu-Chih Wang ${ }^{3, *}$ \\ 1 National Laboratory Animal Center, National Applied Research Laboratories, Taipei 106214, Taiwan; \\ p650214@nlac.narl.org.tw \\ 2 Department of Biotechnology, College of Medical and Health Science, Asia University, \\ Taichung 41354, Taiwan; yichih@asia.edu.tw \\ 3 Graduate Institute of Veterinary Pathobiology, National Chung Hsing University, Taichung 402, Taiwan; \\ ti123103033@gmail.com (Y.-T.H.); jwliao@dragon.nchu.edu.tw (J.-W.L.); gilliankao@hotmail.com (P.-L.K.); \\ miffy19980416@gmail.com (Y.-F.C.); a0928514860@gmail.com (B.-Y.L.); yllin@dragon.nchu.edu.tw (Y.-L.L.); \\ thc@dragon.nchu.edu.tw (T.-H.C.) \\ * Correspondence: ycw2017@email.nchu.edu.tw; Tel.: +886-4-2284-0368 (ext. 92) \\ + These authors contributed equally to the work.
}

check for

updates

Citation: Chuang, H.-L.; Chang, Y.-C.; Huang, Y.-T.; Liao, J.-W.; Kao,

P.-L.; Chen, Y.-F.; Lin, B.-Y.; Lin, Y.-L.; Chen, T.-H.; Wang, Y.-C.

Establishment and Characterization of Feline Mammary Tumor Patient-Derived Xenograft Model. Animals 2021, 11, 2380. https:// doi.org/10.3390/ani11082380

Academic Editor: Adelina Gama

Received: 7 June 2021

Accepted: 7 August 2021

Published: 12 August 2021

Publisher's Note: MDPI stays neutral with regard to jurisdictional claims in published maps and institutional affiliations.

Copyright: (c) 2021 by the authors. Licensee MDPI, Basel, Switzerland. This article is an open access article distributed under the terms and conditions of the Creative Commons Attribution (CC BY) license (https:/ / creativecommons.org/licenses/by/ $4.0 /)$.
Simple Summary: Feline mammary tumor (FMT) is a relatively commonly diagnosed neoplasm in the cat. Development of new veterinary cancer therapies is limited by the shortage of in vivo models that reproduce tumor microenvironment and metastatic progression. In this study, FMT patientderived xenografts (PDX) model were established and primary cell line isolated from orthotopic PDX. The tumor grafts conserve original tumor essential features, including distant metastasis. FMT-PDX represents an available resource for bridging the biology of FMT with preclinical studies of FMT in cats.

Abstract: Feline mammary tumor is a relatively commonly diagnosed neoplasm in the cat. Development of new veterinary cancer therapies is limited by the shortage of in vivo models that reproduce tumor microenvironment and metastatic progression. Four feline mammary tumor orthotopic patient-derived xenograft model (PDX) successfully established in NOD-SCID gamma (NSG) mice. The overall success rate of PDX establishment was $36 \%(4 / 11)$. Histological, immunohistochemical, and short tandem repeat analysis showed a remarkable similarity between patient's tumor and xenograft. The tumor grafts conserve original tumor essential features, including distant metastasis. Primary FMT-1807 cell line isolated from FMT-1807PDX tumor tissue. Tumorigenicity of FMT-1807 cells expanded from PDX was assessed by orthotopic injection into NSG mice. Mice yielded tumors which preserve the lung and liver metastasis ability. This work provides a platform for FMT translational investigation.

Keywords: feline mammary tumor; patient-derived xenograft; cell line

\section{Introduction}

Xenograft models using cancer cell lines has been reported to have several limits, such as not reflecting the patient's drug response sufficiently, limited heterogeneity of the xenograft tumor, and not recapitulating the original tumor microenvironment and tumor-stroma interactions, thus raising concerns that these cell lines may not be fully representative of tumors [1-4]. Patient-derived xenografts (PDX) have been reported to keep histologic appearance, tumor microenvironments, and molecular fidelity to the original tumor. Therefore, the PDX model is becoming a preferred preclinical tool in the development of effective therapeutics [3,4]. Feline mammary tumors (FMTs) are the frequently diagnosed neoplasm primarily between the ages of 10-12 years old female 
cats, have high rate of malignancy. The majority of FMTs are highly aggressive, hormone receptor negative cancer, with poor prognosis characterized by early metastasis in female cats [5-7]. The standard first-line treatment for FMT is aggressive unilateral or bilateral mastectomy. Based on the aggressive behavior and metastatic rate, adjuvant chemotherapy is often recommended. Chemotherapy is restricted by the severe side effects, repeated requirement for anesthesia and high cost. Although good results can be achieved for some cases, it may not necessarily have an appropriate treatment. The development of more effective and least expensive treatments would be beneficial in clinical settings. The establishment of several FMT cell line has been reported [8,9]. But, established FMT cell lines do not preserve the tumor heterogeneity of the original tumor, likely because of the expansion of a homogenous population over period of time in culture. Despite the potential importance of the PDX model for cancer research and clinical translation, limited studies have reported the engraftment of veterinary PDXs [10,11]. It was reported that FMT-PDX implanted subcutaneously in C.B-17 SCID mice with high engraftment success rate but low metastatic incidence [12]. Different strain of mice, orthotopic and ectopic implantation may influence xenograft success rate and metastatic behavior. The engraftment rate of PDX models will affect the cost of the experiment, the length of the experimental period, and the clinical value of pharmacodynamic tests. The present study aims to establish a bank of serially transplantable, orthotopic, subject-derived FMT grafts in NOD.Cg-Prkdc scid IL2 $r g^{t m 1 W j l} /$ SzJ (NSG) mice that retain crucial characteristics of the original tumor specimens.

\section{Materials and Methods}

\subsection{Primary Tumor Samples}

All surgically resected tumor tissue samples were collected after verbal informed consent was received from cat owners at the Nyan cat clinic $(n=6)$, An-Sing animal hospital $(n=3)$ and the veterinary medical teaching hospital of National Chung Hsing University $(n=2)$ under a protocol approved by the Institutional Animal Care and Use Committee (IACUC) of National Chung Hsing University [IACUC Number: $106-73^{\text {R3 }}$ and 108-113]. All tumor tissue samples were collected from cat patients without neoadjuvant chemotherapy.

\subsection{Tissue Implantation of PDXs}

NSG mice were purchased from the Jackson Laboratory and bred in the Research Center for Animal Medicine of the National Chung Hsing University. Mice were administered autoclaved food and water ad libitum. There was always a minimum of three mice per passage of tumor engraftment. Anesthetized the mice using isoflurane (AbbVie Global, Taipei, Taiwan) at $4 \%$ and an oxygen flow of $1 \mathrm{~L} /$ minute (using $4 \%$ isoflurane to induce anesthesia in induction box and then $1.5-2 \%$ isoflurane for the maintenance with the nose-cone). We implanted a single fragment of fresh tumor $\left(1-8 \mathrm{~mm}^{3}\right)$, or injected $1 \times 10^{6}$ primary FMT-1807 cells (isolated from FMT-1807-PDX 3rd passage tumor tissue) in $50 \mu \mathrm{L}$ Dulbecco's modified eagle medium (Thermo Fisher Scientific Hyclone, Waltham, MA, USA) mixed with $50 \mu \mathrm{L}$ Matrixgel Basement Membrane Matrix (BD Biosciences, Bedford, MA, USA) into cleared inguinal mammary fat pads of 6-8-week-old NSG mice. Tumor volumes were calculated weekly using the formula $\frac{1}{2} \times$ length $\times(\text { width })^{2}$. When tumors reached $500-800 \mathrm{~mm}^{3}$, the tumor-bearing mice were isoflurane anaesthetized and PDX tumors were harvested. Donor mice were sacrificed by carbon dioxide asphyxiation. Tumor tissue fragments were transplanted into another three NSG mice, and frozen storage ( $95 \%$ fetal bovine serum $+5 \%$ dimethyl sulfoxide) for later use.

\subsection{Isolation of Primary FMT Cells from PDX Tumor}

Primary tumor cell was collected from the surgical specimen during passage (third passage FMT-1807-PDX). Tissue collected from xenograft tumor (FMT-1807-PDX) was minced into $<5 \mathrm{~mm}^{3}$ pieces and then incubated in PBS with type 3 collagenase $(2 \mathrm{mg} / \mathrm{mL}$, Wor- 
thington Biochemical Corporation, Lakewood, NJ, USA) and hyaluronidase $(10.00 \mathrm{U} / \mathrm{mL}$, Sigma Aldrich, St. Louis, MO, USA) for half hour at $37^{\circ} \mathrm{C}$. After washing with phosphate buffer saline contained $2 \%$ of fetal bovine serum, the digested organoids and single cells were then cultured in Dulbecco's modified eagle medium with $10 \%$ fetal bovine serum (FBS; HyClone Laboratories, Logan, UT, USA) at $37{ }^{\circ} \mathrm{C}$ with $5 \% \mathrm{CO}_{2}$. The solid clusters of tumor cells were formed at first passage. After two days, the culture medium was removed and washed with PBS twice. The organoid clusters of tumor cells treated trypsin-EDTA solution $0.25 \%$ (Gibco, Grand Island, NY, USA) for $15 \mathrm{~min}$, removed the supernatant and grew the remaining cells with FBS-containing DMEM medium.

Flow cytometric analysis was used to examine the expression of the myofibroblast marker $\alpha$-smooth muscle actin $\left(\alpha\right.$-SMA). Cells $\left(1 \times 10^{6}\right)$ were collected in eppendorf and incubated with the $\alpha$-SMA (clone 1A4) antibody (Alexa Fluor ${ }^{\circledR} 488$ Conjugate, eBioscience, San Diego, USA) or Mouse IgG2a Isotype Control (Cell signaling, Danvers, MA, USA) at $37^{\circ} \mathrm{C}$ for $30 \mathrm{~min}$ in dark, followed by immediate analysis on a BD Accuri ${ }^{\mathrm{TM}} \mathrm{C} 6$ Plus Flow Cytometer.

Cell proliferation assays were performed to determine growth rates in culture. Cells were seeded in 24-well plate at $1 \times 10^{5}$ cells/well. Cell number was determined with the Luna Automated Cell Counter (Logos Biosystems, Anyang, Korea) daily for a week. Assays were performed in triplicate.

Lentivirus carried the reporter gene encoding red fluorescence protein (RFP; pLAS2w.RFPC.Ppuro) was purchase from National RNAi Core Facility (Taiwan Academia Sinica). FMT1807 cells were plated in 6-well dishes at $1 \times 10^{5}$ cells/well and incubated with lentivirus in the presence of polybrene $(8 \mathrm{mg} / \mathrm{mL})$ overnight. After 2 days, infected cells (FMT-1807-RFP) were positively selected with puromycin $(2 \mathrm{mg} / \mathrm{mL})$ for a week.

To establish tumorigenicity of FMT-1807-RFP cells, $1 \times 10^{6}$ cells from each patient's cell population was suspended in $100 \mu \mathrm{L}$ of a 1:1 mixture of DMEM medium and Matrigel Matrix and inoculated into the inguinal mammary fat pads of NSG mice. Imaging was performed using the IVIS Imaging System 200 Series (Xenogen Corporation, Alameda, CA, USA). Photon signal intensity was quantified using Living Image ${ }^{\circledR}$ software (Xenogen Corporation).

\subsection{Histopathological and Immunohistochemistry Examination}

Necropsy was performed after euthanasia by carbon dioxide asphyxiation, and tissues (brain, lung, liver, spleen, kidney, femur) were collected and sectioned to confirm metastasis. Samples were fixed in $4 \%$ neutral buffered formalin (femurs decalcified in 10\% EDTA solution for 4 weeks), paraffin embedded, sectioned at $4 \mu \mathrm{m}$ and stained with haematoxylin and eosin. Molecular markers were evaluated immunohistochemically using the avidinbiotin immunoperoxidase method. Sections were deparaffinized by xylene and rehydrated with graded ethanol. Following blocking with $3 \%$ hydrogen peroxide and $1 \%$ BSA, antigens were retrieved with sodium citrate buffer ( $10 \mathrm{mM}$ Sodium citrate, $0.05 \%$ Tween 20 ). The slices were incubated with primary antibodies (Table 1 ) for $1 \mathrm{~h}$ at room temperature and secondary antibodies at room temperature for $30 \mathrm{~min}$. Staining with DAB (Vector Laboratories) was applied to the sections. Subsequent slides were counterstained with Gill's haematoxylin. Expression from immunohistochemical assays was scored by two veterinary pathologists blinded to the origination of the samples. Immunohistochemical semi-quantitative assessment for ER, PR, HER2, CK5/6 or Ki67 were performed following the Allred scoring system guidelines and Soares scoring criteria [12,13]. 
Table 1. Antibodies applied for the immunohistochemical examination.

\begin{tabular}{ccccc}
\hline Target & Clone & Dilution & Manufacturer & Reference \\
\hline ER & 6 F11 & $1: 100$ & Thermo Scientific & Burrai et al., 2010 [14] \\
\hline PR & 10 A9 & $1: 50$ & Meridian Life Science & Burrai et al., 2010 [14] \\
\hline HER2 & CB11 & $1: 200$ & Invitrogen & Soares et al., 2016 [13,15] \\
\hline Pan-cytokertin & AE1/AE3 & $1: 100$ & Dakocytomation & Scott et al., 2011 [16] \\
\hline B-catenin & 14 & $1: 100$ & BD Biosciences & Zappulli et al., 2012 [17] \\
\hline Vimentin & V9 & $1: 100$ & Dakocytomation & Peñafiel-Verdu et al., 2012 [18] \\
\hline CD3 & SP7 & $1: 50$ & Abcam & Furukawa et al., 2017 [19] \\
\hline CD20 & B-Ly1 & $1: 100$ & Santa Cruz & Darbès et al., 1997 [20] \\
\hline Cytokeratin 5/6 & D5/16B4 & $1: 100$ & Sigma-Aldrich & Soares et al., 2016 [13,15] \\
\hline Ki-67 & polyclonal & $1: 500$ & Thermo Scientific & Soares et al., 2016 [13,15] \\
\hline
\end{tabular}

\subsection{Short Tandem Repeat (STR) Analysis}

To confirm lineage identity of every PDX, STR analysis were performed on different chromosomes at 12 loci [12]. Target DNA (10 ng) was amplified by multiplex polymerase chain reaction using fluorescent dye-linked primers for the 12 loci (F53, C08, B04, G11, SRY, FCA441, D09, F124, C12, C09, F85 and D06) listed in Table 2. Amplification was performed using an TopSTR Amplify PCR Kit (TOPGEN, Taiwan) according to the manufacturer's instructions. PCR products generated were mixed with Orange 600 DNA size standard (NimaGen, The Netherlands), electrophoresed on an ABI 3730 genetic analyzer (Applied Biosystems, FosterCity, CA, USA), and analyzed with the GeneMapper ID v3.1 software (Applied Biosystems).

Table 2. Cat multiplex primer sequences and final concentrations.

\begin{tabular}{|c|c|c|c|}
\hline STR Marker & Concentration (uM) & Dye & Primer Sequence \\
\hline \multirow{2}{*}{ F53 } & 0.9 & 6FAM & Forward: CCTATGTTGGGAGTAGAGATCACCT \\
\hline & 0.9 & & Reverse: GTGTCTTGAGTGGCTGTGGCATTTCC \\
\hline \multirow{2}{*}{$\mathrm{C} 08$} & 0.9 & & Forward: GATCCATCAATAGGTAAATGGATAAAGAAGATG \\
\hline & 0.9 & ROX & Reverse: TGGCTGAGTAATATTCCACTGTCTCTC \\
\hline \multirow{2}{*}{ B04 } & 0.9 & 6FAM & Forward: TGAAGGCTAAGGCACGATAGATAGTC \\
\hline & 0.9 & & Reverse: GTGTCTTCCACCCAGGTGTCCTGCTTC \\
\hline \multirow{2}{*}{ G11 } & 1.44 & 6FAM & Forward: ATCCATCTGTCCATCCATCTATT \\
\hline & 1.44 & & Reverse: GGTCAGCATCTCCACTTGAGG \\
\hline \multirow{2}{*}{ SRY } & 0.04 & ROX & Forward: TGCGAACTTTGCACGGAGAG \\
\hline & 0.04 & & Reverse: GCGTTCATGGGTCGTTTGACG \\
\hline \multirow{2}{*}{ FCA441 } & 0.6 & & Forward: GTGTCTTGATCGGTAGGTAGGTAGATATAG \\
\hline & 0.6 & VIC & Reverse: ATATGGCATAAGCCTTGAAGCAAA \\
\hline \multirow{2}{*}{ D09 } & 0.16 & VIC & Forward: CCGAGCTCTGTTCTGGGTATGAA \\
\hline & 0.16 & & Reverse: GTGTCTTTCTAGTTGGTCGGTCTGTCTATCTG \\
\hline \multirow{2}{*}{ F124 } & 0.6 & ROX & Forward: TGTGCTGGGTATGAAGCCTACTG \\
\hline & 0.6 & & Reverse: GTGTCTTCCATGCCCATAAAGGCTCTGA \\
\hline
\end{tabular}


Table 2. Cont.

\begin{tabular}{ccll}
\hline STR Marker & Concentration (uM) & Dye & \multicolumn{1}{c}{ Primer Sequence } \\
\cline { 2 - 4 } C12 & 0.6 & VIC & Forward: GAGGAGCTTACTTAAGAGCATGCGTTC \\
\cline { 2 - 4 } & 0.6 & & Reverse: GTGTCTTAAACCTATATTCGGATTGTGCCTGCT \\
\cline { 2 - 4 } C09 & 1.2 & NED & Forward: AAATTTCAATGTCTTGACAACGCATAAG \\
\hline \multirow{2}{*}{ F85 } & 1.2 & Reverse: GTGTCTTCCAGGAACACCATGTTGGGCTA \\
\cline { 2 - 4 } & 1.44 & NED & Forward: TAAATCTGGTCCTCACGTTTTC \\
\hline \multirow{2}{*}{ D06 } & 1.44 & Reverse: GCCTGAAAATGTATCCATCACTTCAGAT \\
\cline { 2 - 4 } & 1.2 & NED & Forward: CCAAGGAGCTCTGTGATGCAAA \\
\hline
\end{tabular}

\subsection{Statistical Analysis}

All data were expressed as mean $\pm \mathrm{SD}$ and performed student $t$-test analysis for the independent pairwise samples. All statistical comparisons were carried out using SPSS v.13 software. A two-tailed $p<0.05$ was considered to represent a statistically significant difference.

\section{Results}

\subsection{Generation of Tumor Grafts for Feline Mammary Carcinoma}

We orthotopically transplanted 11 fresh primary FMT samples into mammary fat pads of NSG mice. Tumors grew from 4 out of 11 samples, and we successfully maintained these tumor lines through multiple rounds (at least five passages) of serial transplantation (Table 3). Tumors reached approximately $500-800 \mathrm{~mm}^{3}$ volumes prior to collection. Second passage tumors showed similar overall growth rate to the initial founders with a $>90 \%$ successful engraftment and tumor growth rate. After histological review of all successful cases, we found that the resultant tumor grew from PDX models displayed histological preservation to the original patient, characterized by cuboidal to columnar epithelial cells that formed irregular tubular structures (Figure 1A,B), more gland-like characteristics than the tumor growth from primary FMT-1807 cells transplantation (Figure 1C). Nucleolar anisokaryosis was repressed in primary tumor cells. Two tumor grafts (FMT-1701 and FMT-1807) were triple negative basal-like FMT, one tumor graft was luminal A (FMT-1702), another one was HER2-positive (FMT-1806), according to immunohistochemical analysis (Table 1). Tumor growth parameters of each FMT-PDX are shown in Figure 2.

FMT1807 patient tissue

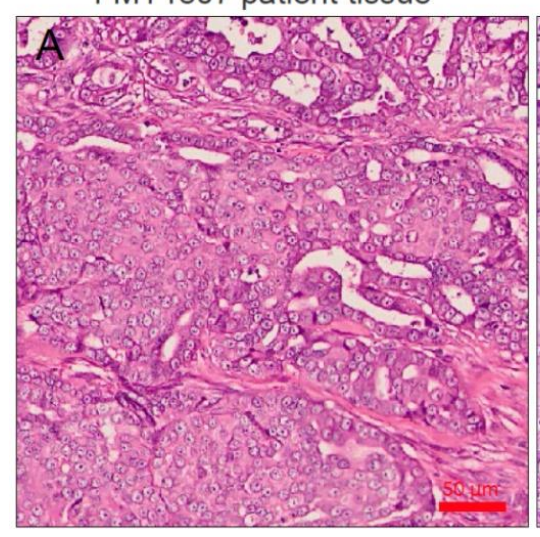

FMT1807 F5 PDX

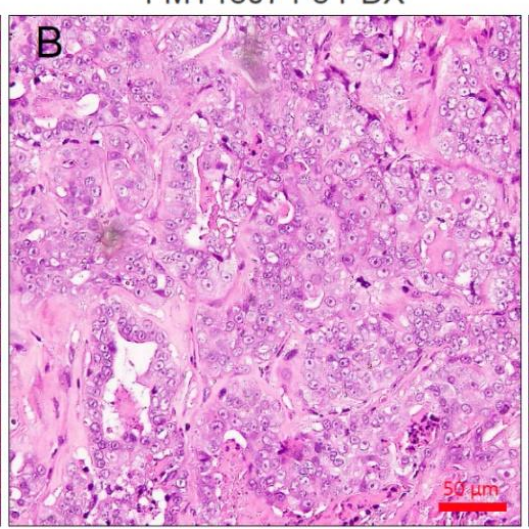

FMT1807 primary cell

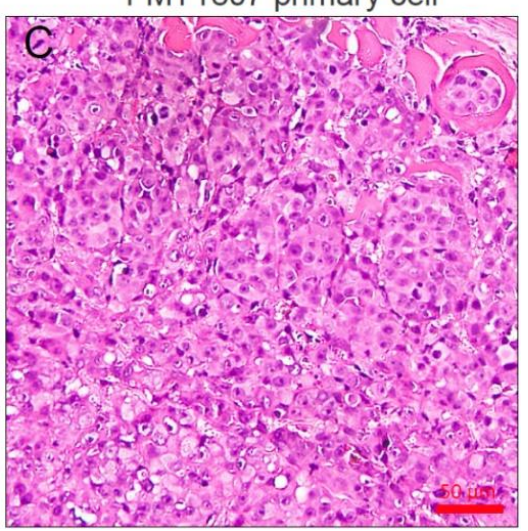

Figure 1. Histological examples of FMT PDXs. H\&E staining was used to assess tumor structure of original patient samples (A), FMT1807-PDX (B) and primary FMT1807 cells implantation (C) samples. Bar $=50 \mu \mathrm{m}$. 
Table 3. Data for each tumor case and corresponding FMT-PDX line.

\begin{tabular}{|c|c|c|c|c|c|c|c|c|c|c|c|c|c|c|}
\hline \multirow[b]{2}{*}{ Case } & \multirow[b]{2}{*}{ Breed } & \multirow[b]{2}{*}{$\begin{array}{l}\text { Tumor } \\
\text { Grade }\end{array}$} & \multirow[b]{2}{*}{$\begin{array}{l}\text { Histological } \\
\text { Type }\end{array}$} & \multicolumn{6}{|c|}{ Subject Information } & \multicolumn{5}{|c|}{ Xenograft Information } \\
\hline & & & & $\begin{array}{l}\text { Histological } \\
\text { Grade }^{\mathrm{a}}\end{array}$ & ER & PR & HER2 & $\begin{array}{l}\text { Molecular } \\
\text { Subgroup }\end{array}$ & Prognosis & ER & PR & HER2 & $\begin{array}{l}\text { Duration in } \\
\text { First Passage } \\
\text { (weeks) }^{\mathrm{b}}\end{array}$ & Metastasis \\
\hline $\begin{array}{l}\text { FMT- } \\
1701\end{array}$ & Mixed & T1N0M0 & Tubulopapillary & II & - & - & - & $\begin{array}{c}\text { Triple } \\
\text { negative } \\
\text { basal-like }\end{array}$ & $\begin{array}{c}\text { Not } \\
\text { available }\end{array}$ & - & - & - & $12-14$ & $\begin{array}{c}\text { Not } \\
\text { detected }\end{array}$ \\
\hline $\begin{array}{l}\text { FMT- } \\
1702\end{array}$ & Mixed & T1N0M0 & Tubulopapillary & I & + & - & - & Luminal A & $\begin{array}{c}\text { Not } \\
\text { available }\end{array}$ & + & - & - & $>6$ month & $\mathrm{LN}$ \\
\hline $\begin{array}{l}\text { FMT- } \\
1806\end{array}$ & $\begin{array}{l}\text { American } \\
\text { shorthair }\end{array}$ & T3N0M0 & Solid & III & - & - & $2+$ & $\begin{array}{c}\text { HER2- } \\
\text { positive }\end{array}$ & $\begin{array}{l}\text { Rrcurrence, } \\
\text { lung } \\
\text { metasta- } \\
\text { sis }\end{array}$ & - & - & $2+$ & $6-7$ & Lung \\
\hline $\begin{array}{l}\text { FMT- } \\
1807\end{array}$ & Mixed & T2N0M0 & Tubulopapillary & III & - & - & - & $\begin{array}{c}\text { Triple } \\
\text { negative } \\
\text { basal-like }\end{array}$ & $\begin{array}{l}\text { Rrcurrence, } \\
\text { lung } \\
\text { metasta- } \\
\text { sis }\end{array}$ & - & - & - & $10-11$ & $\begin{array}{l}\text { Lung, } \\
\text { liver }\end{array}$ \\
\hline
\end{tabular}

${ }^{a}$ According to the Elston and Ellis histologic grading system. ${ }^{\mathrm{b}}$ Interval between transplantation and subpassage to passage $2\left(>500 \mathrm{~mm}^{3}\right)$. LN, lymph node. 


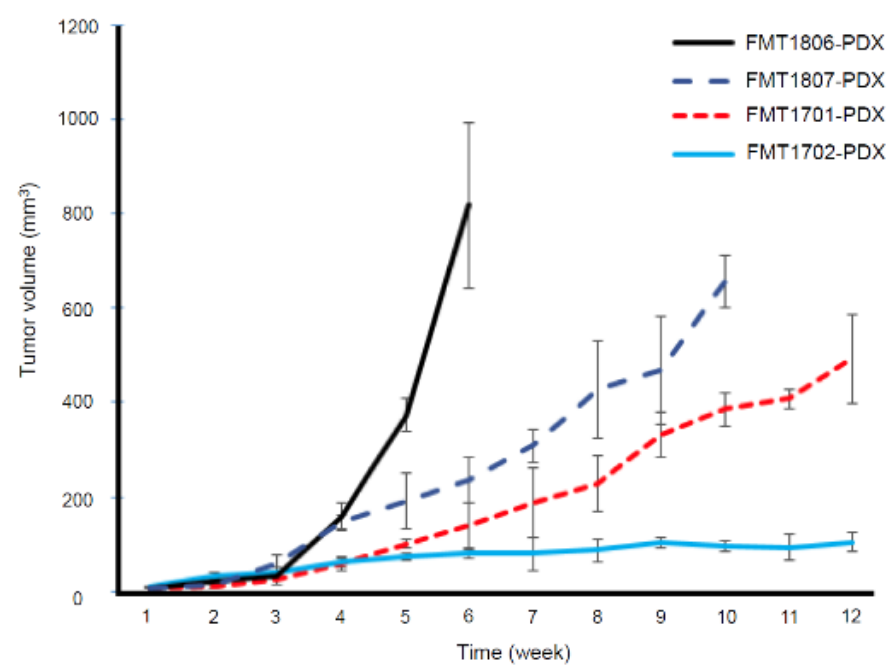

Figure 2. Tumor growth is represented as tumor volume versus time. Six mice were included per group.

We performed microsatellite STR analyses to determine whether the established PDX model retained the identical pattern of the original tumors. We performed PCR using STR markers between tumor tissues from patients and from mice that occurred in established PDX models. As a result, the expression levels of STR markers were observed at the same chromosome loci in parental tumor tissues from patients and fifth passage PDX model (Figure 3). These results showed that the patient and tumor xenografted mouse models preserved the same STR profiles until at least fifth-generation.

In human studies, lymphoma transformation was reported in some PDX cases. After histological review of all successful cases, we found that no lymphomatous transformation or lymphocytic dominant pattern in tumor tissues obtained from mice in tumors stained for anti-CD20 (Figure 4A) or anti-CD3 (Figure 4B) antibodies.
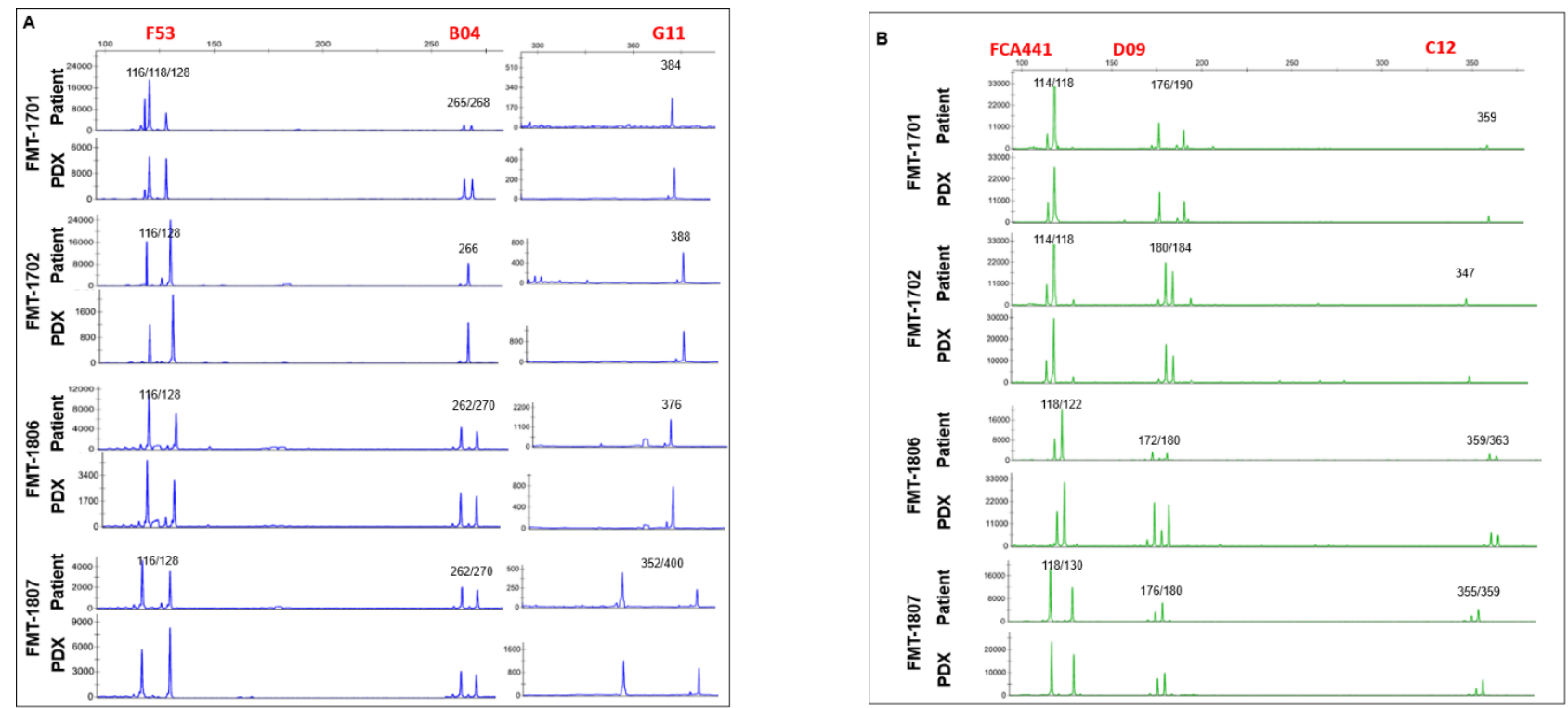

Figure 3. Cont. 

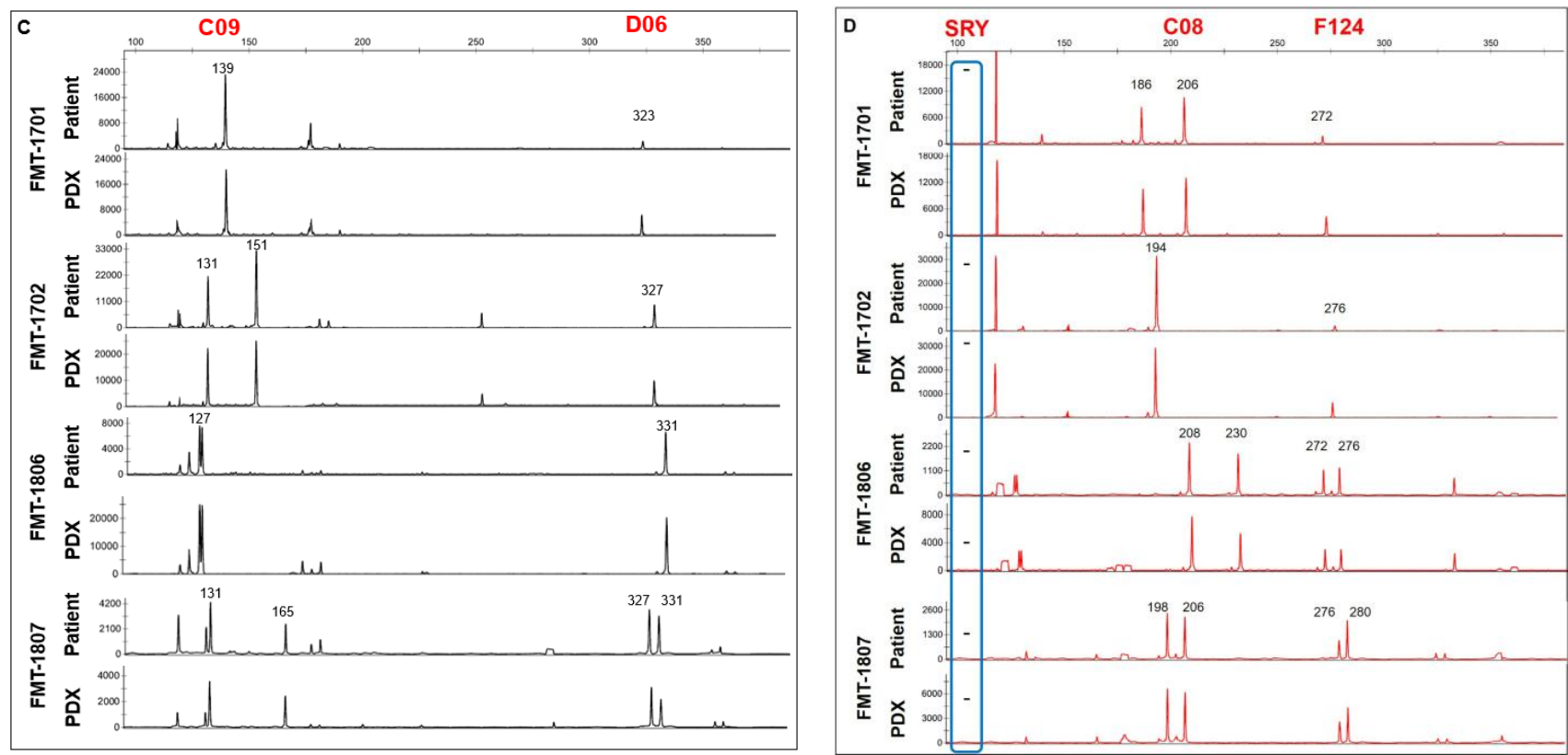

Figure 3. STR amplification of FMTs. Four nanograms of extracted DNA from patient cat tissues or PDX graft tissues were performed cat STR typing. The current dye labels used for the assay include 6-FAM (blue; A), VIC (green; B), NED (black; C) and ROX (red; D). $X$ axis show the allele size, and the $Y$ axis show the intensity.
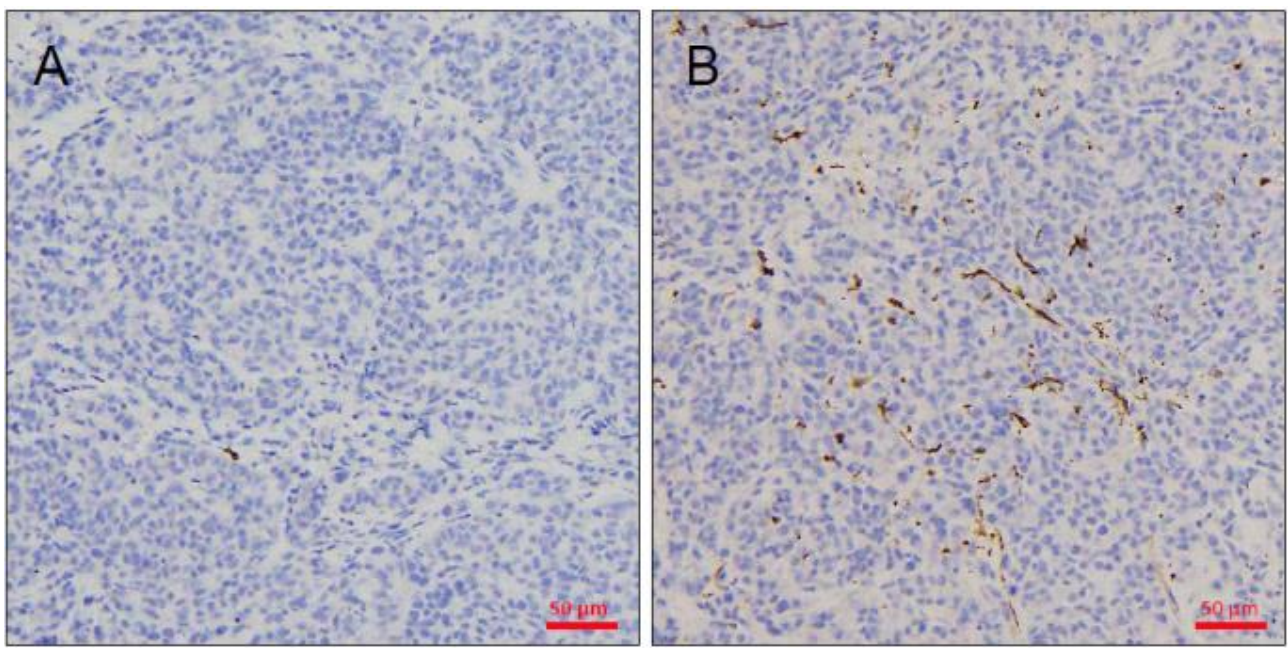

Figure 4. To confirm lymphomatous transformation in PDX tumors, immunohistochemical staining for analysis of CD3 (A), and CD20 (B) expression were performed. The tumor cells were CD3negative and CD20-negative, indicating there were no lymphomatous transformation in PDX tumors. Bar $=50 \mu \mathrm{m}$.

\subsection{Tumor Grafts Emulate Metastasis Seen in PDX Mice}

Tumor metastases in these PDX lines were identified in the lung, liver, spleen, kidneys, and lymph nodes and were examined at the time of necropsy. Tumor metastases were detected grossly, by H\&E staining and immunohistochemical staining. We detected spontaneous metastasis in the axillary node, lung, and liver of mice with tumor grafts (Table 1). All of the metastatic tumors were confirmed as carcinomas by vimentin and pan-cytokeratin (pan-CK) IHC staining (Figure 5). Metastasis frequencies of FMT-1806 PDX and FMT-1807 PDX were 83.3\% (5/6) and 100\% (6/6), respectively (Table 4). 

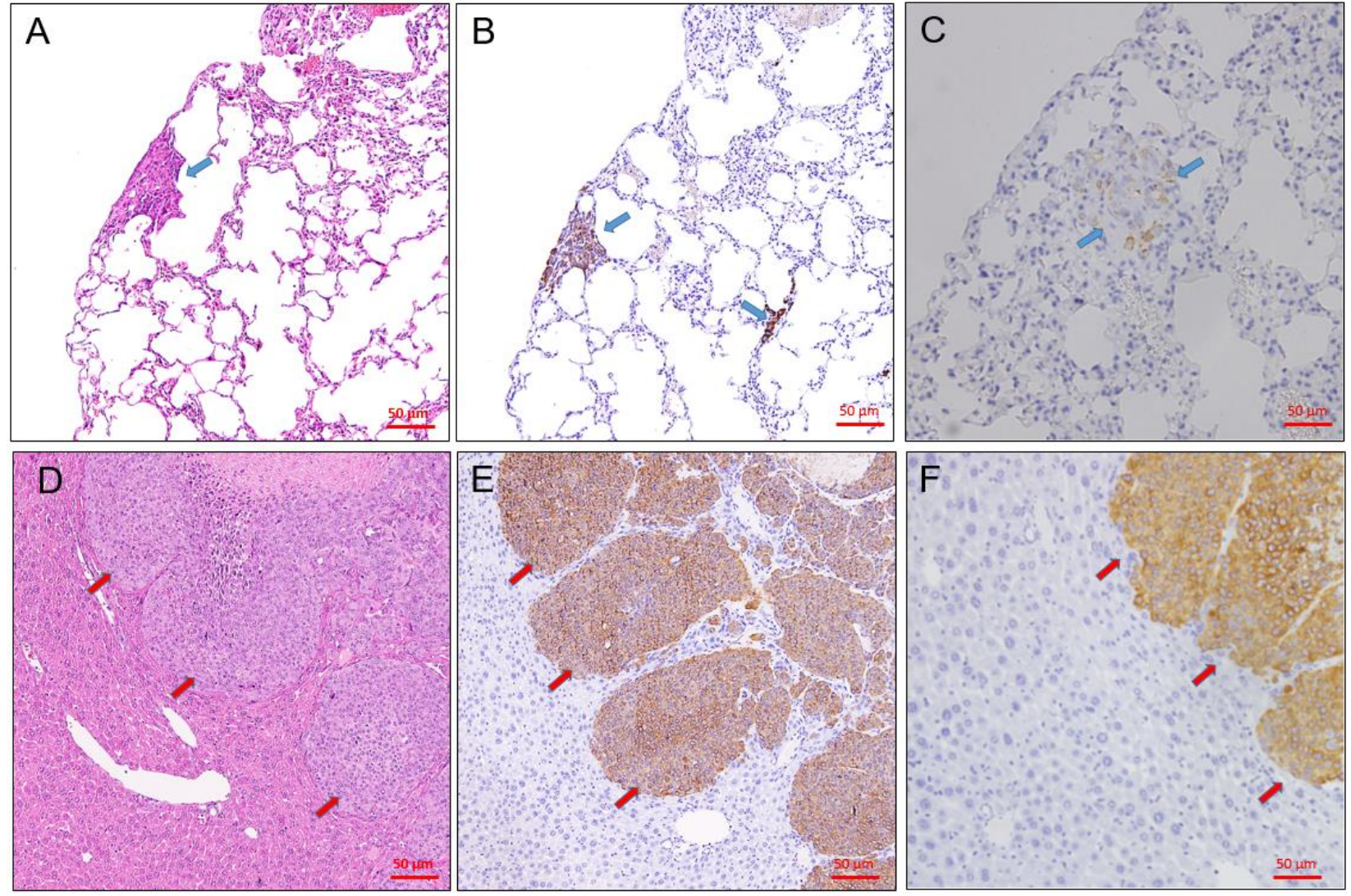

Figure 5. Representative examples of spontaneous metastases from FMT1807-PDX as detected in sections of lung (A-C) and liver (D-F) of mice at necropsy. We identified metastases by H\&E staining $(\mathbf{A}, \mathbf{D})$ or by staining with antibodies specific to vimentin $(\mathbf{B}, \mathbf{E})$ and pan-cytokeratin (pan-CK; C,F). The arrows indicate the metastatic lesion. Bar $=50 \mu \mathrm{m}$.

Table 4. Tumor growth parameters of female mice xenografted with FMT-1806PDX or FMT-1807PDX.

\begin{tabular}{cccc}
\hline PDX & \% of Tumor Growth & Time of $\mathbf{5 0 0} \mathbf{~ m m}^{\mathbf{3}}$ Volume (days) & \% of Animals with Metastasis \\
\hline FMT-1806PDX P3 $(n=6)$ & 100 & $34.2 \pm 2.4$ & $\begin{array}{c}83.3 \% \\
\text { Lung }(5 / 6)\end{array}$ \\
\hline FMT-1807PDX P2 $(n=6)$ & 100 & $56.5 \pm 3.2$ & $100 \%$ \\
Lung (6/6), liver $(2 / 6)$
\end{tabular}

\subsection{Immunohistochemical Characteristics of PDX Tumors}

We analyzed the major molecular characteristics (pan cytokeratin, $\beta$-catenin and vimentin) of original tumors and PDX grafts following five passages in mice (Figure 6). The expressions of these molecular markers revealed similarities between the xenograft tumors and the patients' tumor samples showed that the PDX model retained not only the histology but also the expression of cytological characteristics was preserved.

\subsection{Establishment of Primary FMT Cells from PDX}

Primary FMT-1807 cell line was isolated from FMT-1807PDX tumor formed adherent monolayers in culture (Figure 7A-C) with fast growth kinetics (Figure 7D). Flow cytometric analysis was used to examine the depletion of fibroblasts through differential trypsinization. Cultured FMT-1807 cells were negative for $\alpha$-SMA, indicating the absence of fibroblastic cells (Figure 7E). To confirm tumorigenicity of FMT-1807 cells, the ability of FMT-1807-RFP cells (Figure 7F) to form tumors in NSG mice was determined. FMT-1807-RFP cells were able to grow in vivo (Figure $8 \mathrm{~A}$ ). In addition, metastasis to lung and liver were detected in tumor-bearing animals as shown by IVIS (Figure 8B) and vimentin staining (Figure 8C,D). 

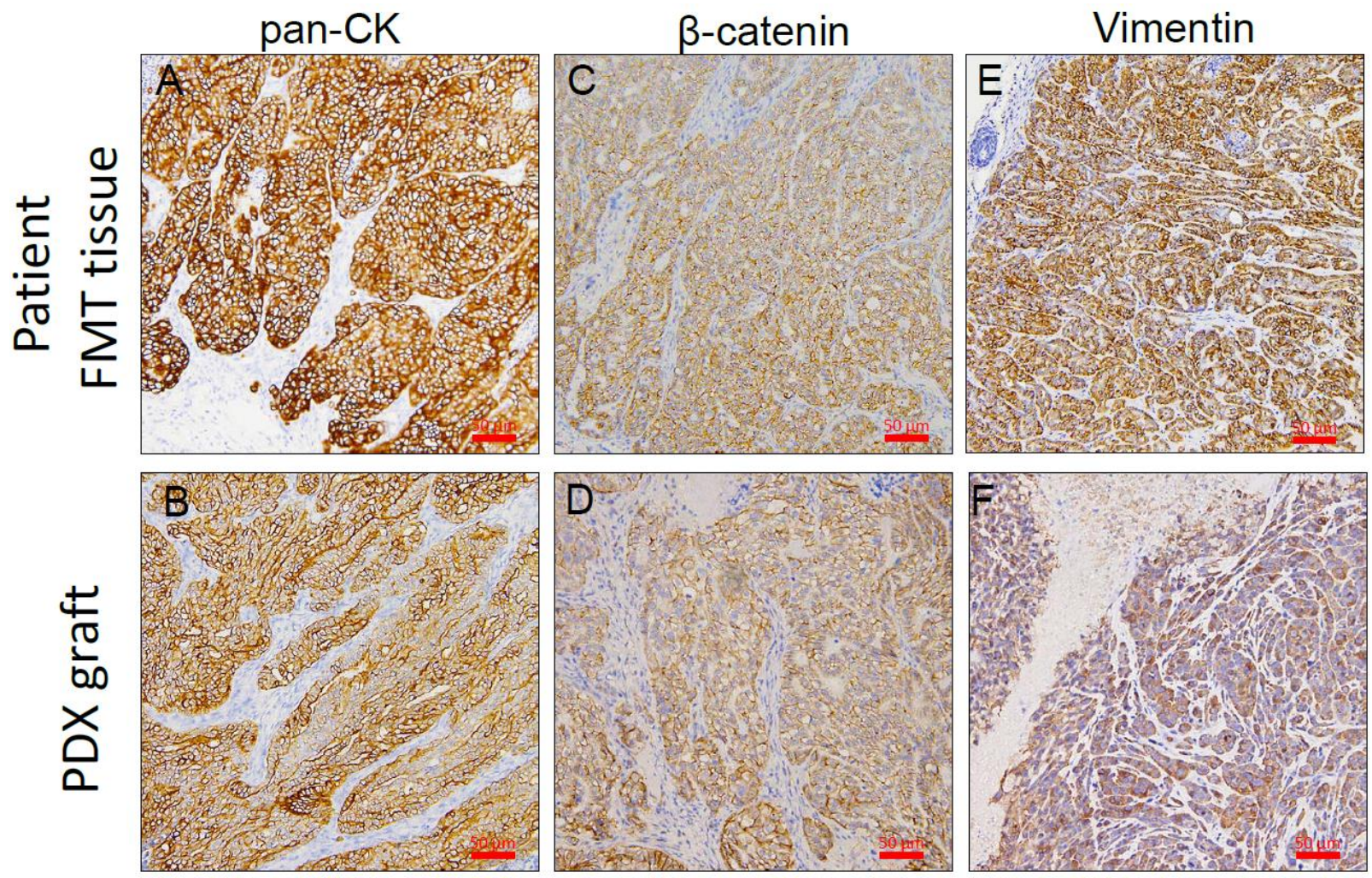

Figure 6. A representative PDX graft (FMT1807) is shown in comparison to the original sample. Sections from the primary FMT of patient cat and from representative PDX grafts from the same individual are shown. Shown are antibody stains for pan-cytokeratin (pan-CK; A,B), $\beta$-catenin $(\mathbf{C}, \mathbf{D})$ and vimentin $(\mathbf{E}, \mathbf{F})$. Positive antibody signals are shown in brown, and the hematoxylin counterstain is shown in blue. Bar $=50 \mu \mathrm{m}$.
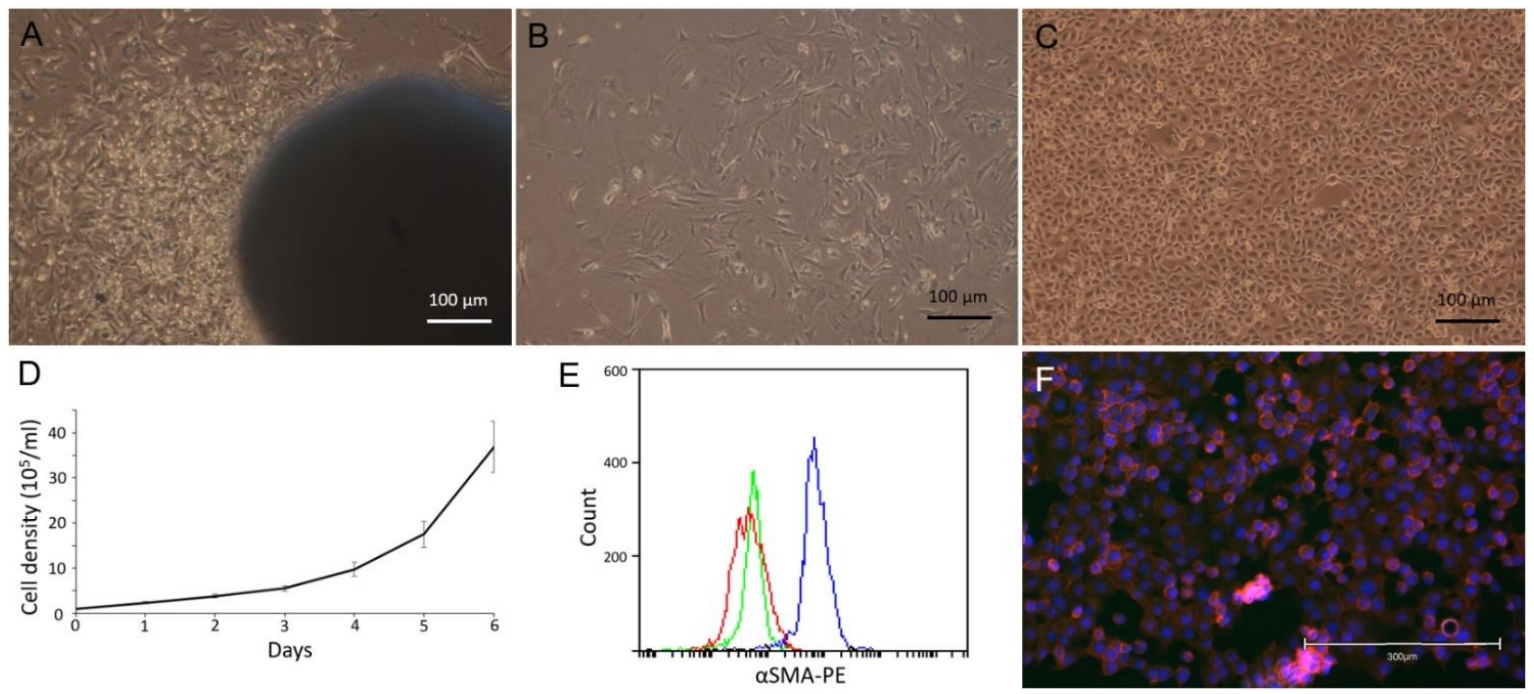

Figure 7. Isolation of primary FMT cells from PDX tumor. (A) Mixed primary culture (organoid) derived from FMT1807PDX xenograft tumor. (B) Mesenchymal cells derived by differential trypsinization from FMT-1807PDX xenograft tumor, cultured in DMEM supplemented with 10\% FBS. (C) Morphology of primary FMT-1807 cells after differential trypsinization. (D) In vitro growth kinetics of FMT-1807 cells. (E) Flow cytometric analysis of $\alpha$-SMA expression of primary FMT-1807 cells (red) and mesenchymal cell derived by differential trypsinization (blue). Isotype control (green) indicates staining of cells with the isotype control antibody. (F) Confocal image of purified RFP-tagged FMT-1807 cells. 


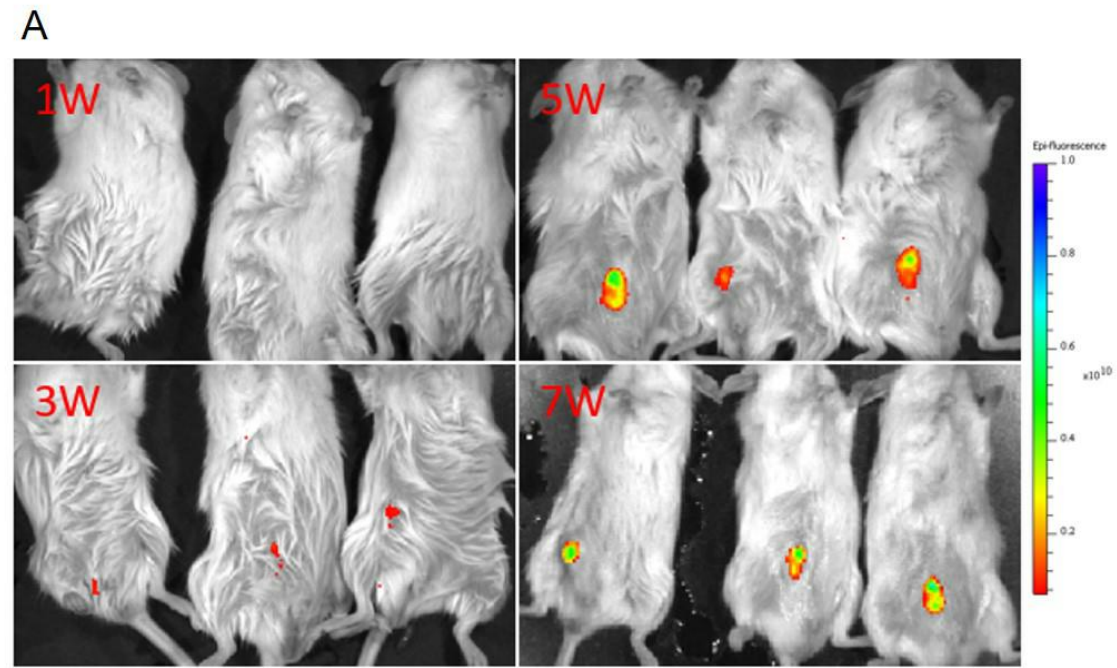

B
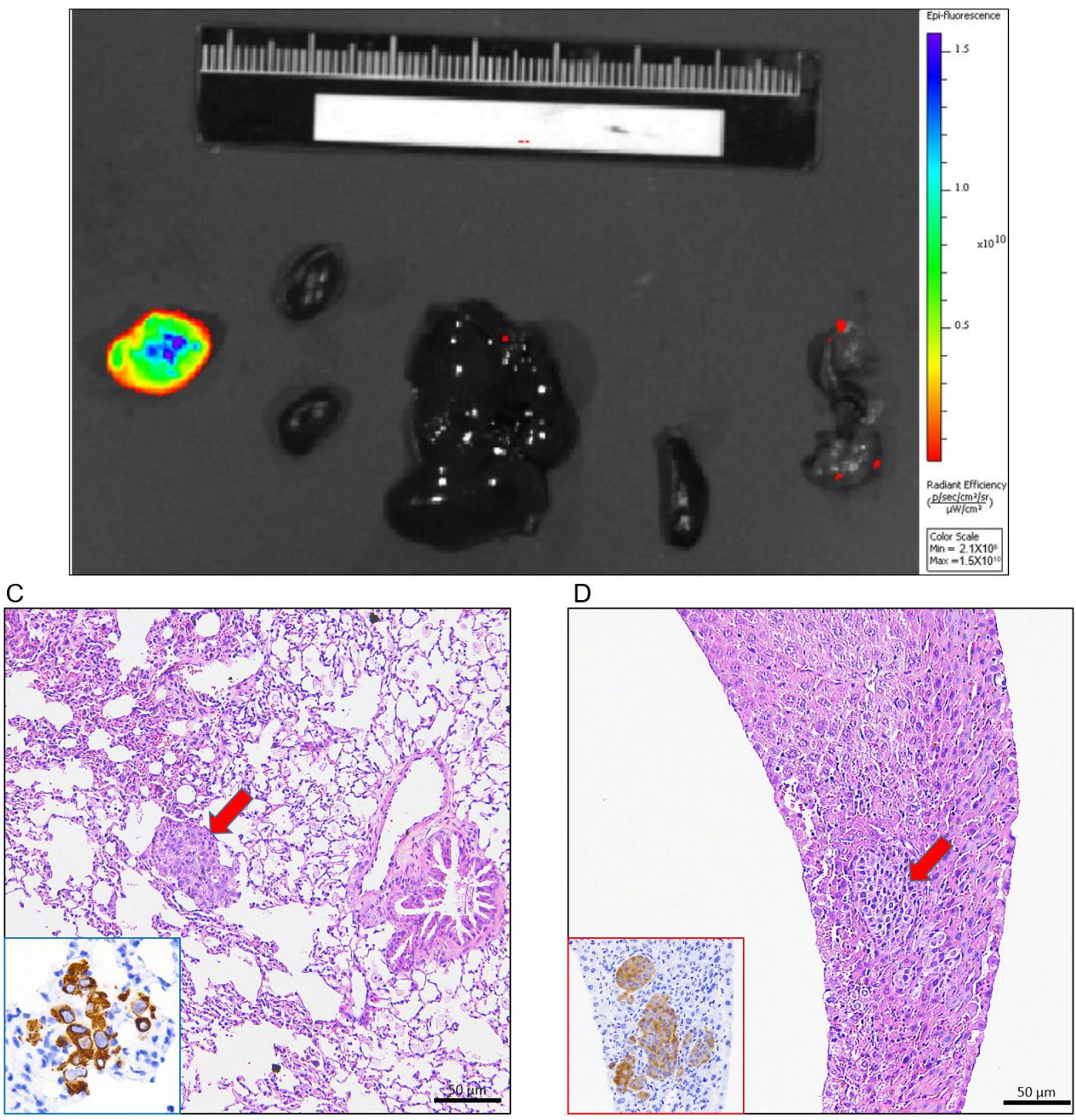

Figure 8. Analysis of NSG mice engrafted withFMT-1807-RFP cells. (A) Optical imaging of mice bearing tumors induced by FMT-1807-RFP cells into the inguinal mammary fat pads monitored via ex vivo IVIS imaging. The time course is indicated. (B) Tumor spontaneous metastasis to organs monitored via IVIS imaging (from left to right: kidney, liver, spleen and lung). Histopathology of metastatic tumors in mouse models with FMT-1807-RFP cells. H\&E staining and IHC staining for vimentin of paraffin sections of lung (C) and liver metastases (D). The arrows indicate the metastatic lesion. 


\section{Discussion}

In the present study, we established a bank of serially transplantable, orthotopic mammary tumor grafts that retained critical features of the original tumor specimens from cats with FMC. The result shows that the FMT-PDX grafts maintain key features of the original tumors, including histopathology and immunohistochemical markers. The establishment of several FMT cell lines has been reported [6,11], but only few reports about feline PDX [11]. The take rate of FMT-PDX is higher than other type cat cancer [11,21], canine tumor [22,23] or human tumor [24], it might be suggested that high malignancy of FMT. Lower metastasis incidence found in ectopic FMT-PDX [11] suggested that the preservation of the tumor microenvironment in subcutaneous xenograft models may differ from orthotopic FMT implantation.

Animal models are useful in vivo tools for the molecular studies of tumor progression and metastasis. One of the important features between the FMTs in patient cats and their corresponding PDX grafts is their ability to spontaneously metastasize. To create an effective translational model, we isolated purified populations of FMT cells in culture derived from our FMT-1807PDX model murine xenograft. FMT cell line is important resource for studying cancer cell biology, as well as for developing new strategies against cancer cell validation in vitro and in vivo. Numerous FMT cell lines have been reported and characterized $[6,11]$. Most of the previously established FMT cell lines used in research were derived from primary or metastasis FMTs, whereas our new cell lines were derived from murine patient tumor xenografts. We have found this approach to be beneficial due to the relatively larger amounts of tumor tissue from which to culture cells, as primary patient tumor specimens are usually more limited in volume. Also, murine xenografts are potentially endlessly expandable, so it is possible to isolate new cell lines repeatedly after the original tumor resection has taken place. The primary FMT-1807 cell has demonstrated efficient tumorigenicity when orthotopic injected into NSG mice. Therefore, this approach can be used to enables concurrent study of patient tumor xenografts and their derived cell line to be experimented with both in vitro and in vivo.

\section{Conclusions}

In summary, a PDX model of FMT was developed in NSG mice. The FMT-PDX model is relatively easy to carry out and may serve as a platform for further cancer research and translational work.

Author Contributions: Conceptualization, Y.-C.W., Y.-C.C. and H.-L.C.; methodology, Y.-C.W.; validation, J.-W.L., T.-H.C. and Y.-L.L.; investigation, Y.-T.H., B.-Y.L., P.-L.K. and Y.-F.C.; writing-original draft preparation, Y.-C.W.; writing — review and editing, P.-L.K. and T.-H.C.; project administration, Y.-C.W.; funding acquisition, Y.-C.W. All authors have read and agreed to the published version of the manuscript.

Funding: This research was funded by Ministry of Science and Technology (Taiwan), grant number MOST106-2313-B-005-059—and MOST107-2311-B-005-011-MY3.

Institutional Review Board Statement: The animal procedures used in this study were approved by the Institutional Animal Care and Use Committee (IACUC) of National Chung Hsing University [IACUC Number: $106-73^{\mathrm{R} 3}$ and 108-113], and verbal informed consent was obtained from all cat owners.

Data Availability Statement: The datasets used and/or analyzed during the current study are available from the corresponding author on reasonable request.

Conflicts of Interest: The authors declare no conflict of interest. The funders had no role in study design, data collection and analysis, decision to publish, or preparation of the manuscript. 


\section{References}

1. Di Masi, J.A.; Reichert, J.M.; Feldman, L.; Malins, A. Clinical approval success rates for investigational cancer drugs. Clin. Pharmacol. Ther. 2013, 94, 329-335. [CrossRef]

2. Cho, S.Y.; Kang, W.; Han, J.Y.; Min, S.; Kang, J.; Lee, A.; Kwon, J.Y.; Lee, C.; Park, H.S. An integrative approach to precision cancer medicine using patientderived xenografts. Mol. Cells 2016, 39, 77-86. [PubMed]

3. Hidalgo, M.; Amant, F.; Biankin, A.V.; Budinská, E.; Byrne, A.T.; Caldas, C.; Clarke, R.B.; de Jong, S.; Jonkers, J.; Mælandsmo, G.M.; et al. Patient-derived xenograft models: An emerging platform for translational cancer research. Cancer Discov. 2014, 4, 998-1013. [CrossRef]

4. Tentler, J.J.; Tan, A.C.; Weekes, C.D.; Jimeno, A.; Leong, S.; Pitts, T.M.; Arcaroli, J.J.; Messersmith, W.A.; Eckhardt, S.G. Patientderived tumour xenografts as models for oncology drug development. Nat. Rev. Clin. Oncol. 2012, 9, 338-350. [CrossRef] [PubMed]

5. Chang, Y.C.; Chuang, H.L.; Yin, J.H.; Liao, J.W.; Chen, T.H.; Wang, Y.C. Significance of sphingosine kinase 1 expression in feline mammary tumors. BMC Vet. Res. 2019, 15, 155. [CrossRef]

6. Burrai, G.P.; Mohammed, S.I.; Miller, M.A.; Marras, V.; Pirino, S.; Addis, M.F.; Uzzau, S.; Antuofermo, E. Spontaneous feline mammary intraepithelial lesions as a model for human estrogen receptor- and progesterone receptor-negative breast lesions. BMC Cancer 2010, 10, 156. [CrossRef] [PubMed]

7. Hayes, H.M., Jr.; Milne, K.L.; Mandell, C.P. Epidemiological features of feline mammary carcinoma. Vet. Rec. 1981, 108, 476-479. [CrossRef]

8. Borges, A.; Adega, F.; Chaves, R. Establishment and characterization of a new feline mammary cancer cell line, FkMTp Cytotechnology 2016, 68, 1529-1543. [CrossRef]

9. Granados-Soler, J.L.; Junginger, J.; Hewicker-Trautwein, M.; Bornemann-Kolatzki, K.; Beck, J.; Brenig, B.; Betz, D.; Schille, J.T.; Murua Escobar, H.; Nolte, I. TiHo-0906: A new feline mammary cancer cell line with molecular, morphological, and immunocytological characteristics of epithelial to mesenchymal transition. Sci. Rep. 2018, 8, 13231. [CrossRef]

10. Frazier, J.P.; Beirne, E.; Ditzler, S.H.; Tretyak, I.; Casalini, J.R.; Thirstrup, D.J.; Knoblaugh, S.; Ward, J.G.; Tripp, C.D.; Klinghoffer, R.A. Establishment and characterization of a canine soft tissue sarcoma patient-derived xenograft model. Vet. Comp. Oncol 2017, 15, 754-763. [CrossRef]

11. Michishita, M.; Ohtsuka, A.; Nakahira, R.; Tajima, T.; Nakagawa, T.; Sasaki, N.; Arai, T.; Takahashi, K. Anti-tumor effect of bevacizumab on a xenograft model of feline mammary carcinoma. J. Vet. Med. Sci. 2016, 78, 685-689. [CrossRef]

12. Maruo, K.; Sugimoto, T.; Suzuki, K.; Shirota, K.; Ejima, H.; Nomura, T. Xenotransplantation and high tumorigenicity of feline tumors in SCID mice. J. Vet. Med. Sci. 1995, 57, 967-969. [CrossRef]

13. Soares, M.; Correia, J.; Peleteiro, M.C.; Ferreira, F. St Gallen molecular subtypes in feline mammary carcinoma and paired metastases-disease progression and clinical implications from a 3-year follow-up study. Tumor Biol. 2016, 37, 4053-4064. [CrossRef] [PubMed]

14. Eirew, P.; Steif, A.; Khattra, J.; Ha, G.; Yap, D.; Farahani, H.; Gelmon, K.; Chia, S.; Mar, C.; Wan, A.; et al. Dynamics of genomic clones in breast cancer patient xenografts at single-cell resolution. Nature 2015, 518, 422-426. [CrossRef] [PubMed]

15. Soares, M.; Correia, J.; Rodrigues, P.; Simões, M.; de Matos, A.; Ferreira, F. Feline HER2 protein expression levels and gene status in feline mammary carcinoma: Optimization of immunohistochemistry (IHC) and in situ hybridization (ISH) techniques. Microsc. Microanal. 2013, 19, 876-882. [CrossRef] [PubMed]

16. Kuperwasser, C.; Chavarria, T.; Wu, M.; Magrane, G.; Gray, J.W.; Carey, L.; Richardson, A.; Weinberg, R.A. Reconstruction of functionally normal and malignant human breast tissues in mice. Proc. Natl. Acad. Sci. USA 2004, 101, 4966-4971. [CrossRef]

17. Mattar, M.; McCarthy, C.R.; Kulick, A.R.; Qeriqi, B.; Guzman, S.; de Stanchina, E. Establishing and maintaining an extensive library of patient-derived xenograft models. Front. Oncol. 2018, 8, 19. [CrossRef]

18. Dobrolecki, L.E.; Airhart, S.D.; Alferez, D.G.; Aparicio, S.; Behbod, F.; Bentires-Alj, M.; Bentires-Alj, M.; Brisken, C.; Bult, C.J.; Cai, S.; et al. Patient-derived xenograft (PDX) models in basic and translational breast cancer research. Cancer Metastasis Rev. 2016, 35, 547-573. [CrossRef] [PubMed]

19. Scott, V.L.; Wallace, K.; Mays, S.; Ryan, P.; Coats, K.S. An immunohistochemical assay to detect trophoblasts in frozen feline placenta. J. Vet. Diagn. Investig. 2011, 23, 275-281. [CrossRef]

20. Darbès, J.; Majzoub, M.; Hermanns, W. Evaluation of the cross-reactivity between human and feline or canine leucocyte antigens using commercially available antibodies. J. Vet. Diagn. Investig. 1997, 9, 94-97. [CrossRef]

21. Ladiges, W.C.; Van Hoosier, G.L., Jr. Heterotransplantation of feline malignant tumors in nude thymusless mice. Am. J. Vet. Res. 1980, 41, 840-842. [PubMed]

22. Sugimoto, T.; Maruo, K.; Imaeda, Y.; Suzuki, K.; Shirota, K.; Ejima, H.; Endo, S.; Nomura, T. Xenotransplantation of canine tumors into severe combined immunodeficient (SCID) mice. J. Vet. Med. Sci. 1994, 56, 1087-1091. [CrossRef] [PubMed]

23. Umeki, S.; Ema, Y.; Suzuki, R.; Kubo, M.; Hayashi, T.; Okamura, Y.; Yamazaki, J.; Tsujimoto, H.; Tani, K.; Hiraoka, H.; et al. Establishment of five canine lymphoma cell lines and tumor formation in a xenotransplantation model. J. Vet. Med. Sci. 2013, 75, 467-474. [CrossRef] [PubMed]

24. Behbod, F.; Kittrell, F.S.; LaMarca, H.; Edwards, D.; Kerbawy, S.; Heestand, J.C.; Young, E.; Mukhopadhyay, P.; Yeh, H.W.; Allred, D.C.; et al. An intraductal human-in-mouse transplantation model mimics the subtypes of ductal carcinoma in situ. Breast Cancer Res. 2009, 11, R66. [CrossRef] [PubMed] 